\title{
Factors associated with selling price of dairy calves at livestock marts
}

\section{N. McHugh ${ }^{1,2}$, A.G. Fahey ${ }^{2}$, R.D. Evans ${ }^{3}$, D.P. Berry ${ }^{1}$}

${ }^{1}$ Teagasc, Moorepark Dairy Production Research Centre, Fermoy, Co. Cork, Ireland, ${ }^{2}$ School of Agriculture, Food Science and Veterinary Medicine, University College Dublin, Belfield, Dublin 4, Ireland, ${ }^{3}$ Irish Cattle Breeding Federation, Highfield House, Bandon, Ireland

Email: noirin.mchugh@teagasc.ie

Introduction In Ireland livestock marts remain an important marketing outlet for dairy calves, with dairy calves accounting for $26 \%$ of total dairy cattle mart movements (Department of Agriculture, Fisheries, and Food, 2008). Previous US studies have attempted to quantify the factors associated with calf price (Troxel and Barham, 2007), however little is known on the association between calf price and factors such as dam age, heterosis, recombination, calving difficulty, and whether the animal was a singleton or twin. The objective of this study was to determine the factors associated with selling price received for dairy calves in Irish livestock marts. Results from this study may be used to help farmers make improved management decisions, and provide information for bio-economic models for evaluating production systems or estimating economic values.

Materials and methods In the present study calves were defined as animals from dairy cows sold between 2 days of age and 12 weeks of age. A total of 306,640 calf price records from 71 livestock marts in Ireland between the years 2000 to 2008 inclusive, were available. In Ireland, calves from dairy herds are generally sold in livestock marts from a couple of days of age. Not all calves are sold in livestock marts and some are sold privately among individuals; no data on these sales were available. To accurately quantify associations, only animals sold individually at the livestock marts were retained. Animals were removed if their herd of origin or the mart of sale were unknown. Only calves sold for a price between $€ 2$ and $€ 450$ were retained. Animals retained had to have at least $66 \%$ of their breed fraction known. Following all edits 53,838 calves remained. Factors associated with calf price were determined using mixed linear models (ASReml; Gilmour et al., 2009). Mart, date of sale nested within mart, and herd nested within year of sale were included as random effects. Fixed effects considered for inclusion in the models were: year of sale, month of sale, gender, age of animal at selling, parity of dam, calving ease, whether the animal was born as a singleton or twin, the proportion of the 10 most common dairy and beef breeds used in Ireland, heterosis, and recombination loss, as well as interactions.

Results The mean selling price for all calves in the dataset was $€ 157$ (standard deviation $=€ 79$ ). The majority of calves (57\%) were sold between January and April and 91\% of all calves were sold before 42 days of age, with an abrupt drop in sales at day 42. Crossbred, male, singleton calves from older cows received a price premium $(\mathrm{P}<0.001)$ and the price paid increased linearly with age. The association between age and price, however, differed by gender, with a greater increase in males ( $€ 1.15$ per day of age) compared to females ( $€ 0.94$ per day of age). The difference in calf price from different parity dams was small, with the exception of calves from first parity cows where they, on average, received $€ 14.03$ less $(\mathrm{P}<0.001)$ than calves from mature cows (i.e. parity $\geq 5$ ). Each $1 \%$ increase in proportion Belgian Blue was worth an extra $€ 1.89$ in males compared to $€ 1.06$ in females (Figure 1).

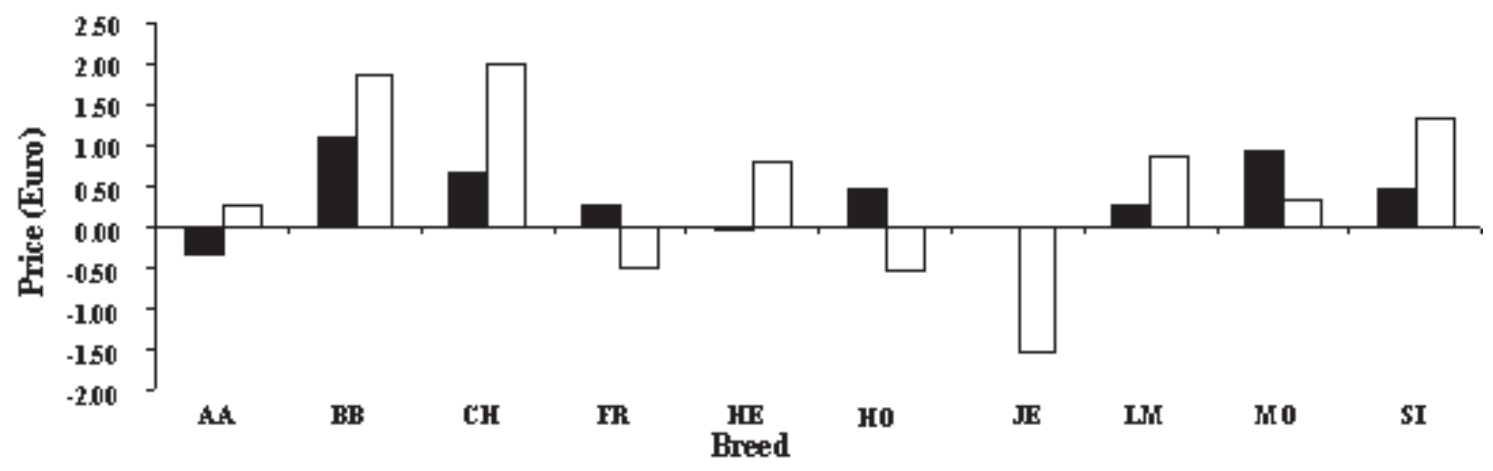

Figure 1 Change in calf price per one percent increase in breed proportion for female ( $\square$ ) and male ( $\square$ ) calves across breeds.

$\mathrm{AA}=$ Aberdeen Angus, $\mathrm{BB}=$ Belgian Blue, $\mathrm{CH}=$ Charolais, $\mathrm{FR}=$ Friesian, $\mathrm{HE}=$ Hereford, $\mathrm{HO}=\mathrm{Holstein}, \mathrm{JE}=\mathrm{Jersey}, \mathrm{LM}=$ Limousin, SI $=$ Simmental.

Conclusion. Factors such as breed, birth type, calving difficulty, heterosis, age at selling, gender, and age of dam were shown to have varying associations with the price obtained for an animal. Purchasers were willing to pay premium prices for older, crossbred, singleton male calves born from older cows. Although prices varied across years, there were similarities in season trends; namely the age of the animal and the seasonality of selling. Knowledge of these factors and the seasonal trends in sales can help farmers to maximise prices attainable for their animals and thus the profitability of their production system.

\section{References}

Barham, B.L. and Troxel, T.R. 2007. Journal of Animal Science 85, 3434-3441.

Department of Agriculture, Fisheries and Food, Ireland 2008. CMMS Statistics Report 2008.

Gilmour, A.R., Gogel, B.J., Cullis, B.R., and Thompson, R. 2009. ASReml User Guide, Release 3.0. 